\title{
Repensar la justicia desde un enfoque de géneros
}

Viviana Laura Beigel

Universidad Champagnat

La perspectiva de géneros en la justicia es una herramienta metodológica que contribuye a promover la igualdad en las prácticas y en las sentencias, pero que además colabora en reducir las brechas que existen entre el derecho escrito y el acceso efectivo a respuestas judiciales que aseguren la equidad. Los procesos no son neutros, sino que están impregnados por los parámetros culturales que normalizan la discriminación por razones de género. Por eso, repensar la justicia desde un enfoque de géneros es un verdadero problema de derechos humanos, que obligatoriamente debe ser abordado por los Estados que han ratificado las Convenciones Internacionales en la materia.

Una de las tareas más difíciles en estos tiempos, es la de modificar los patrones socioculturales y los estereotipos de género que menoscaban y discriminan a las mujeres y a las personas trans o de género diverso. La cultura patriarcal se inserta de manera sigilosa y sutil en cada una de las actividades que desarrollamos, generando violencias epistémicas. En palabras de Siegel (2000), los estereotipos de género son resilientes, dominantes y persistentes. Son dominantes socialmente cuando se articulan a través de los sectores sociales y las culturas y son socialmente persistentes en cuanto se articulan a lo largo del tiempo.

Las prácticas cargadas de prejuicios discriminatorios no son ajenas a la justicia. Es así como una mirada que permita hacer visibles las asimetrías de poder y las desventajas en razón de los géneros tendrá un impacto en las decisiones que permita mejorar el derecho de acceso a la justicia en un pie de igualdad.

La ex Reportera Especial de Naciones Unidas para la Violencia contra las Mujeres consideró que "la persistencia de las normas culturales y sociales, las creencias tradicionales y los estereotipos de género negativos fueron los obstáculos más comúnmente citados por los gobiernos para el logro de la igualdad de género en todas las regiones" (Ertürk, 2004).

Las prácticas alejadas de la debida diligencia, estereotipadas y discriminatorias conducirán siempre a soluciones injustas y revictimizantes. Se trata de un fenómeno estructural que es transversal a todas las instituciones y que afecta especialmente a aquellos sujetos cuyas identidades son calificadas mediante estereotipos negativos de género.

La Corte IDH viene desarrollando una labor intensa en la materia, identificando estereotipos de género en diversos precedentes. Entre sus fallos, podemos citar el 
caso "Artavia Murillo y otros vs. Costa Rica", en el que ha identificado estereotipos de género que son incompatibles con el derecho internacional de los derechos humanos, considerando que los mismos deben ser erradicados (Corte IDH, sentencia 28/11/12, Párr. 302).

Para hacer realidad la tutela judicial en clave de géneros resulta fundamental diseñar estrategias judiciales dirigidas a materializar el derecho a la igualdad ya que, si bien está proclamado de manera formal en las normas del derecho internacional de los derechos humanos, este principio muchas veces no se hace efectivo.

La perspectiva de géneros es una herramienta para el fortalecimiento del acceso a la justicia, ya que permite advertir cuando las personas están atravesadas por relaciones de poder marcadas por violencias y discriminaciones.

Debe tenerse en cuenta, además, que otros factores sociales, culturales, económicos, étnicos o geográficos pueden afectar de manera diferenciada a las mujeres, a las personas trans o de género diverso, produciendo situaciones de múltiple discriminación. Por ello, en el análisis del caso, resulta fundamental identificar adecuadamente a las partes, sus diferencias y sus asimetrías y el contexto específico en el que se desarrolla el conflicto llevado a los tribunales.

La justicia debe aplicar un enfoque de género interseccional y sensible ante las violaciones a los derechos humanos para evitar la desprotección debido a la falta de recursos legales eficaces que sean acordes a los contextos y a las vulnerabilidades. Cuando concurren y se entrecruzan diferentes categorías de discriminación, las decisiones judiciales deberán interseccionar esas desventajas mediante un análisis complejo para arribar a una solución que restituya los derechos vulnerados.

El desarrollo jurisprudencial de la Corte IDH, en casos como "Fernández Ortega vs. México", ha sido receptivo del concepto de interseccionalidad. En esta sentencia, la Corte IDH particularmente señaló que "...el Estado al no tomar en cuenta la situación de vulnerabilidad de la víctima, basada en su idioma y etnicidad, incumplió su obligación de garantizar, sin discriminación, el derecho de acceso a la justicia". En esta sentencia, el tribunal interamericano entendió que “...es indispensable que los Estados otorguen una protección efectiva que tome en cuenta sus particularidades propias, sus características económicas y sociales, así como su situación de especial vulnerabilidad, su derecho consuetudinario, valores usos y costumbres..." (Corte IDH. Sentencia de 30/08/11. Parr 200).

La interseccionalidad es una herramienta de análisis multidimensional que tiene por finalidad garantizar la efectiva aplicación de los derechos humanos sin perder de vista el contexto y la experiencia discriminatoria particular. Utilizada en las decisiones de la justicia, permitirá alcanzar una visión íntegra y específica del caso concreto en miras de una solución reparadora.

\section{Repensando claves para una justicia con perspectiva de géneros}

La justicia argentina se encuentra en un punto de inflexión y de reformulación a partir de la decisión política del Poder Ejecutivo Nacional de avanzar hacia reformas que, entre otras cosas, buscan incorporar la perspectiva de géneros. 
En este marco, el Decreto 635/2020 promovió la creación de un Consejo Consultivo para el Fortalecimiento del Poder Judicial y del Ministerio Público conformado por prestigiosos juristas, con el fin de elaborar un dictamen con propuestas y recomendaciones. Los expertos convocados fueron Hilda Kogan, Claudia Sbdar, María del Carmen Battaini, Alberto Beraldi, Inés Weinberg de Roca, Enrique Bacigalupo, Andrés Gil Domínguez, Gustavo Ferreyra, León Arslanian, Marisa Herrera y Omar Palermo.

Estos expertos propusieron un conjunto de reformas estructurales que incluyen acciones positivas para contrarrestar el denominado "techo de cristal" en el ámbito de la justicia, la incorporación de criterios de igualdad para el ejercicio de las licencias laborales, la promoción de la diversidad de género, la paridad de género y la representación federal en la integración del Poder Judicial, del Consejo de la Magistratura y del Ministerio Público Fiscal. Se propuso, además, la realización de diagnósticos con perspectiva de género para proponer modificaciones en las reglamentaciones y prácticas vigentes.

Las propuestas elaboradas en este informe constituyen un gran aporte para mejorar las desigualdades estructurales arraigadas en este poder del Estado, el que sin lugar a duda requiere profundas modificaciones para avanzar hacia una justicia con perspectiva de géneros.

En este marco, entiendo que las reformas estructurales necesarias para hacer efectivo el nuevo paradigma basado en un enfoque de géneros y de derechos humanos en la justicia, deben ser acompañadas por modificaciones normativas a fin de garantizar la aplicación práctica de los principios de igualdad y de no discriminación por razones de género.

Entre las reformas procesales urgentes, se encuentra la de incluir medidas de acción positivas para la efectiva protección de los derechos humanos de las mujeres y de las diversidades en las decisiones judiciales. En este aspecto, surge la necesidad de incorporar en las normas, el enfoque de género interseccional sensible ante las violaciones a los derechos humanos bajo pena de nulidad. La interseccionalidad resulta potencialmente útil para denunciar las múltiples desigualdades que han condenado a importantes sectores de la población al "silencio" y a la invisibilidad por parte del Estado y sus políticas (Magliano y Ferreccio, 2017), por ello es un elemento de análisis que no puede estar ausente.

En el mismo sentido, las herramientas interpretativas utilizadas hasta el momento para el análisis de los hechos deberán complementarse con la perspectiva de géneros como metodología exigible para la validez de las decisiones jurisdiccionales. Ya no basta con la utilización de la sana crítica racional como método interpretativo, es necesario avanzar en razonamientos multidimensionales con enfoque de géneros para desarticular los estereotipos negativos que provocan decisiones judiciales discriminatorias.

Las normas deberán, además, descalificar las sentencias que contengan argumentos contrarios a los principios de la no discriminación, de la igualdad y del pleno respeto a la dignidad humana. En esta línea de análisis, la conceptualización utilizada en las sentencias deberá ser cuidadosa al incluir un análisis ajustado a las convenciones internacionales de derechos humanos que protegen los derechos de las mujeres y de las diversidades, resultando inadmisibles las decisiones fundadas en patrones socioculturales basados en prejuicios de género o en premisas que avalen la inferioridad o superioridad de cualquiera de los géneros. Significantes discriminatorios derivados de los roles tradicionales de género, como aquellos que se fundan en la idea de la "buena madre" o del "buen padre de familia" no pueden ser admitidos en las sentencias actuales. 
En el mismo sentido deben erradicarse del lenguaje judicial conceptos cosificantes y deshumanizantes como los que son utilizados en el marco de los procesos penales por narcotráfico, en los que se califica a las personas que transportan estupefacientes en su cuerpo como "mulas", por cuanto se trata de una forma de expresión que constituye un trato indigno, inhumano, cruel y degradante. Estas referencias no son inocentes, sino que provienen de una justicia de clase, que estigmatiza y margina. Esta justicia, sin perspectiva en derechos humanos y géneros, revictimiza a las personas al calificar como animales de carga a quienes han sufrido una situación de extrema violencia y explotación.

Una mirada judicial respetuosa de los derechos humanos requiere normas que impongan nulidades a este tipo de construcciones simbólicas.

Es necesario que las decisiones de nuestros tribunales utilicen un lenguaje no sexista, no discriminatorio, accesible y acorde a los estándares del derecho internacional de los derechos humanos. Las sentencias redactadas en base a concepciones androcéntricas, heteronormativas y sexistas dan lugar a construcciones autoritarias en las que se privilegian los rasgos asociados con la masculinidad y la consiguiente devaluación y desprecio de aquellas cosas que se codifican como femeninas (Fraser, 1997).

La justicia debe dejar atrás las discriminaciones propias de un poder arcaico y patriarcal mediante nuevas formas de comunicación respetuosas de la autopercepción, de la identidad de género, de la diversidad y de los derechos de las mujeres. De este modo, las sentencias darán lugar a representaciones simbólicas que contribuyan a erradicar los estereotipos de género negativos, las violencias y las asimetrías de poder.

\section{Repensando las prácticas judiciales}

Las diferencias entre lo público y lo privado, la división sexual del trabajo y la jerarquización de valores fundados en la heteronormatividad solo pueden ser comprendidas si las estructuras y las relaciones sociales se analizan desde la perspectiva de géneros. Es necesario dejar atrás la vieja normalidad inserta en el derecho que regula las relaciones jurídicas con una mirada androcéntrica, que solo incluye el trabajo que se realiza en la esfera pública dejando de lado las tareas domésticas o de cuidado y que no atiende los impactos profundos que tiene la violencia de género en las distintas esferas de la vida en nuestras sociedades.

Incluir la categoría de género en las prácticas judiciales lleva implícito un análisis relativo a "la síntesis histórica que se da entre lo biológico, lo económico, lo social, lo jurídico, lo político, lo psicológico y lo cultural" (Lagarde, 2004). Por eso, las políticas de los poderes judiciales que se funden en un diagnóstico hecho con perspectiva de género permitirán mejorar el acceso a la justicia de la población. Si repensamos nuestro poder judicial en función del sistema de géneros, podremos diseñar matrices de análisis para la emisión de sentencias respetuosas del derecho internacional de los derechos humanos.

Es importante señalar que este enfoque no compromete la imparcialidad, ni la independencia de quienes imparten justicia, ya que no se está proponiendo en ningún caso, decidir el proceso a favor de las mujeres, sino, cosa distinta, buscan mecanismos metodológicos que permitan a magistrados y magistradas reconocer y considerar si se está ante un caso en que existe una discriminación de género, visibilizar los estereotipos que contribuyen a perpetuar la desigualdad, analizar su particular condición a la luz de las normas jurídicas nacionales e internacionales pertinentes y garantizar que sea objeto de un tratamiento que permita el acceso efectivo a la justicia de todas las personas... (Muñoz Sánchez, 2018) 
Las medidas de acción positiva necesarias para erradicar las desigualdades y las discriminaciones en los procesos judiciales deben traducirse en prácticas concretas. Desde el primer momento en que una persona accede al sistema judicial deben activarse las buenas prácticas y una mirada con perspectiva de géneros que tenga en cuenta los impactos diferenciados y las asimetrías de poder que existen en cada caso concreto.

Es fundamental partir desde el respeto a la autopercepción de género de quien solicita el auxilio de la justicia y desde la puesta en valor de la autodeterminación de las personas como límite para llevar adelante acciones de protección, de reparación integral o de sanción según corresponda a la situación planteada.

La matriz de análisis del caso en cuestión deberá tomar en consideración el contexto en el que se desarrollan los hechos y las relaciones de poder existentes en la situación particular. Se deben identificar los derechos vulnerados o reclamados y comprender cabalmente quiénes son las partes procesales, sin que se pueda soslayar que todas ellas están atravesadas por una cultura que puede validar situaciones discriminatorias. Además, se debe comprender la petición de las partes de manera interseccional, determinando si concurren las vulnerabilidades en el caso concreto.

La valoración de las pruebas debe realizarse con perspectiva de géneros, garantizándose la plena libertad probatoria, en especial cuando se trata de aquellas relaciones jurídicas vinculadas a la discriminación o a la violencia, dado que a veces no se logra la prueba directa. Es necesario identificar cuáles son los roles de cada persona en la relación, los estereotipos de género, las manifestaciones sexistas y la posible existencia de situaciones que conllevan a la invisibilización de las violencias.

En este sentido, al analizar el caso, es imprescindible dilucidar la existencia de relaciones de subordinación e incluso de sometimiento, por cuanto el modo en que la violencia de género impacta en la disminución o anulación de la autodeterminación de quien la padece, puede llevar a una decisión de exculpación de responsabilidad por falencias en la esfera de la voluntad.

Para lograr una justicia con perspectiva de géneros, además, es necesario que las prácticas judiciales se desarrollen en base a los parámetros que impone la debida diligencia reforzada, concepto que ha sido desarrollado en diversos precedentes, resoluciones y recomendaciones del sistema universal de protección de los derechos humanos. ${ }^{1}$

En la solución del caso se deben revisar detenidamente las normas que resultan aplicables para determinar si estas producen un impacto diferenciado y discriminatorio por razones de género. Se deben, también, aplicar al caso los estándares del derecho internacional de los derechos humanos y los precedentes jurisprudenciales del sistema universal de protección, de modo tal de fortalecer los argumentos tendientes a modificar los patrones socioculturales discriminatorios y violentos hacia las mujeres, las personas trans y de género diverso. Esta justicia, así reformulada y repensada, tendrá en miras la reparación integral de los perjuicios sufridos y la restitución de todos los derechos vulnerados.

1 El deber de debida diligencia para prevenir, sancionar y erradicar hechos de violencia contra las mujeres nace de las obligaciones genéricas de la Convención Americana de Derechos Humanos y de las obligaciones específicas que impone la Convención Interamericana para Prevenir, Sancionar y Erradicar la Violencia contra la Mujer. La Corte IDH, además, ha establecido que, en un contexto de violencia, subordinación y discriminación histórica contra las mujeres, los compromisos internacionales "imponen al Estado una responsabilidad reforzada". "González y otras ("Campo Algodonero') vs. México”, párrafo 283. Este criterio fue reiterado por la Corte en los fallos “Velásquez Paiz y otro vs. Guatemala", "Véliz Franco y otros vs. Guatemala” y “J. vs. Perú". 
Para que el servicio de justicia deje de ser una mera declaración de posibilidades y se transforme en una herramienta para la realización de los derechos humanos fundamentales de todas las personas, necesitamos profundizar las instancias de capacitación de los operadores y operadoras del sistema, fomentar la reflexión, promover diagnósticos interseccionales y procurar el análisis de las prácticas en clave de géneros.

La perspectiva de género debe ser incorporada como política del Poder Judicial si se pretende cumplir con los compromisos internacionales. 


\section{Bibliografía}

》 Arbeláez de Tobón, L. y Ruiz González, E. (2018). Cuaderno de buenas prácticas para incorporar la perspectiva de género en las sentencias. Poder Judicial de Chile. Eurosocial. Programa para la cohesión social en América Latina.

»Erturk, Y. (2004). Considering the Role of Men in Agenda Setting: Conceptual and Policy Issues. Feminist Review № 78: 7.

»Fraser, N. (1997). Iustitia Interrupta: Reflexiones críticas desde la posición "postsocialista". 48, capítulo 1. En Holguín, M. yJaramillo, I. C. (trads.). Colección Nuevo Pensamiento Jurídico, pp. 31-33. Bogotá, Universidad de los Andes, Siglo del Hombre.

"Lagarde, M. (2204). La multidimensionalidad de la categoría género y del feminismo. En González Marín, M. Metodología de los estudios de género, p. 26. México, UNAM-IIES.

》Magliano, M. J. y Ferreccio, V. (2017). Interseccionalidades que condenan: gestos coloniales del sistema jurídico en Argentina. Revista Crítica Penal y Poder, № 13: 112-127, octubre. Barcelona, Observatorio del Sistema Penal y los Derechos Humanos, Universidad de Barcelona.

" Muñoz Sánchez, A. (2018). Ministra Corte Suprema de Justicia de Chile. Seminario Internacional "Buenas prácticas de la administración de justicia en la aplicación del principio de igualdad. La perspectiva de género, un desafío para la no discriminación". Santiago de Chile, abril 18.

»Naciones Unidas, Asamblea General (1979). Convención sobre la eliminación de todas las formas de discriminación contra la mujer.

» Organización de Estados Americanos (OEA) (1994). Convención interamericana para prevenir, sancionar y erradicar la violencia contra la mujer "Convención de Belém do Pará".

"Siegel, R. B. (2000). Discrimination in the Eyes of the Law: How "Color Blindness" Discourse Disrupts and Rationalizes Social Stratification. California Law Review, № 88.

" UFEM. (2017). Unidad Fiscal Especializada en Violencia contra las Mujeres. Jurisprudencia y doctrina sobre debida diligencia reforzada en la investigación de crímenes de género. Ministerio Público Fiscal. Procuración General de la Nación. Disponible en: https://www.mpf.gob.ar/ufem/files/2017/o8/Ufem_ Dossier-2.pdf 
